\title{
Bingöl Şehir Merkezine Yakın Devlet Yollarında Yağmur Suyu Hasadı Ve Hidroelektirik Potansiyelinin İncelenmesi
}

\section{İhsan GÜZEL}

Bingöl Üniversitesi, Inşaat Mühendisliği Bölümü, Bingöl

iguzel@bingol.edu.tr ORCID: 0000-0002-9368-8902

\author{
Ahmet BENLi* \\ Bingöl Üniversitesi, Inşaat Mühendisliği Bölümü, Bingöl \\ abenli@bingol.edu.tr ORCID:0000-0002-3005-6123,Tel: (426) 2160012 (1949)
}

Geliş: 15.05.2019, Revizyon:04.08.2019, Kabul Tarihi: 27.08.2019

\section{$\ddot{\mathbf{O} z}$}

Dünyada vazgeçilmez bir doğal kaynak olan suyun kullanabilir kısmı olan tatlı su kaynakları; nüfus artışı ve beraberinde ihtiyaç duyulan gıda ürünleri için tarımda daha fazla kullanımının yanı sıra şehirleşen sanayileşen bölgelerde ihtiyacı ve kirliliğinin artması ve iklim dĕ̆işikliği etkisiyle erişimi ve kalitesinin olumsuz etkilemektedir. Insan yaşamının en önemli ögesi olan su aynı zamanda günümüz insanlarının ve ülkelerin önemli gereksinimlerinden olan elektrik enerjisinin temininde kullanılacak temiz ve yenilenebilir bir kaynak olması, günümüzde elektrik enerjisi üretiminde en fazla miktarda kullanılan ve gün geçtikçe tükenen fosil kaynakl yakıtlara karşı önemini artırmaktadır. Uluslararası alanda su ile ilgili sorunları kesin bir biçimde ele alındı̆̆ Dünya Su Forumunun, "Çözüm Zamanı”, "Geleceğimiz Için Su” temalarıyla yapılan Fransa (2012) ve Güney Kore (2015) formlarında tatlı su kaynaklarının erişimi ve katledesinde olumsuz etkilenmelerin genel olarak ĕ̆itim, yeterli finans kaynakları sağlanması, su depolanması ve yağmur suyu hasadının yapılması, yerel yönetim desteklenmesi, manevi ve etik değerlerin ve ilkelerin tanınması ve su sektöründe karar alma süreçlerinde dikkate alınmasıyla azaltılabileceği belirtilmiştir. Su baskısı altında olan ülkemizin enerji ihtiyacı da bulunmakta olup bu çalışmada Bingöl Şehir Merkezine yakın devlet yollarının dağlık arazi kesimlerinden geçen kısımlarında yağmur suyu hasadı ile toplanan suyun cazibeli akışla kullanılması ve hidroelektrik potansiyeli tespit edilmeye çalışılmıştır. Yağmur suyunun karayolu projelerine göre toplanmasına uygun olan ayrıca düşü yüksekliğinin fazla olduğu; Karlıvva Ayr-Solhan güzergahının 5960 m'lik kısmında toplanan yağmur sularının $18320 \mathrm{~m}$ çelik cebire borularla taşınarak yıllık 75,940,314.85 Watt enerji üretileceği hesaplanmasına karşın işletme ve yapım maliyetleri bakımından ekonomik olmadiğg; bu nedenle. Bingöl şehir merkezine yakın Kurudere-Bingöl, Ilıcalar-Bingöl, Karlıova Ayr-Solhan güzergâhlarının yağmur suyu hasadına ve bu hasadın cazibeli akışla yerleşim yerlerine getirilmesi uygun olan kisımlarında yıllık toplanacak su miktarının su kaynaklarına ve ülke ekonomisine katkısı araştırılmıştır.

Anahtar Kelimeler: Karayolu, Yağmur Suyu Hasadı, Hidroelektrik Enerji, Evsel Su Kullanımı

\footnotetext{
* Yazışmaların yapılacağı yazar
}

DOI: 10.24012/dumf.565949 


\section{Giriş}

Yaşam için vazgeçilmez bir doğal kaynak olan suyun dünyada kullanılabilir kısmı olan tatlı su kaynaklarının erişimi ve kalitesi genel olarak; nüfus artışı ve beraberinde besin ve gıda için suyun daha fazla tarımda kullanılması yanı sıra şehirleşen sanayileşen bölgelerde su ihtiyacı ve su kirliliği artmasından dolayı olumsuz yönde etkilenmektedir. Bu durum 2018 Yılında Dünya Ekonomik Forumunda hazırlanan Küresel Risk Raporunda iklim değişikliğinin etkileriyle birlikte gelecekte küresel riskler arasında su krizleriyle karşılaşlabileceği belirtilmiştir (1).

Uluslararası alanda su ile ilgili sorunları kesin bir biçimde ele alındığı Dünya Su Forumunun, Fransa (2012) ve Güney Kore (2015) formları "Çözüm Zamanı", "Geleceğimiz İçin Su" temalarıyla yapılmış olup; birçok konuyla beraber su gıda ve enerji ilişkisi, su ve insanlığın geleceği, sürdürülebilir kalkınma için su depolanmas1, 2025 yılından sonra dünya sularının geleceği, kurak alanlarda su kıtlığı, yerel su yönetimleri ve sistemleri için sürdürülebilir finans kaynaklarının sağlama, su ve sağlıklı suya erişimi sağlama sorumluluğu verilen yerel yönetimlere insan kaynağ gerekli finansman desteğinin ve firsatlarının sağlanması, yerel su yönetimleri ve sistemleri için sürdürülebilir finans kaynaklarının sağlama, su eğitimini geliştirerek kapasite geliştirme, enerji için su-su için enerji, manevi ve etik değerlerin ve ilkelerin tanınması ve su sektöründe karar alma süreçlerinde dikkate alınması, su ve gıda güvenliği, akışa geçen suların daha verimli kullanılması için tarım alanlarında yağmur suyu hasadı, şehirlerde kurak bölgelerde yağmur suyu hasadı konuları oturumlarda ele alınmıştır $(2,3)$. Gelecekte su ihtiyaçlarının karşılanmasında katkıda bulunacak olan yağmur suyu hasadiyla ilgili olarak; yağmur suyu hasadiyla depolanan suların tarım (4) ve evsel ihtiyaçlar için kullanılması (5),su tasarrufu(6), ekolojik (ağaçlandırma vb.), çevresel korumayı destekleme, kaynaklardan temin edilen su sistemlerinin yapımıyla, yağmur suyu sistemlerinin yapımında karbondioksit emisyonunu salınımı karşılaştırması (7),yenilenebilir enerji kaynağı sudan, güneş enerjisinden yararlanılamadığı yüksek yağış alan bölgelerde çatılarda yağmur suyu hasadı ile toplanan sudan pico-hidroelektrik toplama cihazı aracilığıyla kırsal elektrifikasyon temini (8),yağmur suyu hasadı sistemlerinin enerji yoğunluğu(9),çiftçilerin karayolları yüzeylerinden yağmur suyu hasadı yapma teknikleri (10),kentsel alanlarda bulunan yollarda yağmur suyu toplama potansiyeli (11) çalışmaları yapılmıştır.

Ülkeler fosil yakıtlardan çeşitli yenilenebilir güneş, rüzgâr ve su gibi kaynaklara geçtikçe yenilenen kaynaklardan enerji üretimi önemini artmaktadır. Literatürde karayolu yüzeylerinden yağmur suyu hasadı ile toplanan sudan hidrolikelektirik potansiyeli ile ilgili çalışmalar tespit edilemediğinden bu çalışmada Bingöl ili sınırlarında Karayolları Genel Müdürlüğü sorumluğunda dağllk araziden geçen Elâzı ğ il Sınır1-Bingöl, Bingöl-Solhan, Karlıva-Bingöl devlet yolu güzergâhların Bingöl şehir merkezine yakın kısımlarında yağmur suyunun kullanım potansiyeli ve yağmur suyu hasadı ile toplanan suyun hidrolik enerji potansiyeli araştırılacaktır.

\section{Yağmur Suyu Hasadı}

$\mathrm{Su}$ kaynakları, üzerindeki talebin giderek artışının yanında zaman ve konuma göre bu kaynağın arzu edilen miktar ve kalitede bulunmaması, mevcut su kaynaklarının ekonomik, çevresel ve sosyal faydalar içinde en verimli şekilde kullanımını yani yönetimini gerekli kılmaktadır. Su kaynakları yönetimi, doğal çevrim içerisinde suyun insanlar tarafindan gerek nicelik gerekse nitelik olarak en verimli şekilde ekonomik, sosyal ve çevresel faydalar içinde sistematik olarak kullanımı anlamına gelmektedir (12).

$\mathrm{Su}$ yönetimi çerçevesinde yağış sularından maksimum fayda sağlayacak bir strateji geliştirmeyi amaçlayan su hasadı yöntemi, yağmur sularının ve yüzey akışına geçen suların toplanıp biriktirilmesi, bitkisel ve hayvansal üretim için gerekli olan suyun temini ile evsel tüketim için gerekli suyun sağlanmasıdır. En geniş anlamıyla su hasadı "verimli kullanım için su akışının toplanması" olarak tanımlanmaktadır (13). Yağmur suyu hasadı, yerleşim bölgelerinin çatı yüzeylerinde, yerel havzalarda (arazi) akışa 
gecen yağmur sularının yakalanması, akarsu yataklarında mevsimsel sel sularının yakalanması, yağışın düştüğü yüzeyde toplanması ve toprağa depolanması dış su hasadı ile başka bir yerdeki bir yüzeyde yağışlardan kaynaklanan akıntıların toplanması ve depolanması, havzaların yönetimi ile su tasarrufu şeklinde yapılmaktadır $(14,15)$.

Yağmur Suyu hasadının avantajları;

-Kentsel yeşillik için İlave su temini ve toprak nem seviyesinin arttırılması

-Yeraltı su seviyesinin arttırılması (yapay olarak yeniden doldurma)

-Kentsel taşkınların azaltılması

-Yeraltı suyu veya diğer su temini kaynaklarını desteklenmesi suretiyle su temini maliyetini düşürülmesi,

-Acil durumlar için iyi kullanabilir su kaynağ olmas1.

- Bakım maliyetleri düşük ve kolay basit teknolojiler kullanılması.

-Su kaynaklarının yetersiz olduğu bölgelerde alternatif kaynak olarak kullanılabilir olması

-Yağmur suyu deşarjlarını, kentsel taşkınları ve kanalizasyon arıtma tesislerinin aşırı yüklenmesinin azaltılması

- Kıyı bölgelerinde, yeraltı suyuna şarj edildiğinde, tuzluluk oranını düşürerek iyi kalitede su sağlaması

-Yağmur suyu toplama sistemleri basit olması nedeniyle bireyler tarafindan kolayca benimsenmesi

- Tarımsal verimde artış sağlaması

-Orman arazisinin iyileştirmesi

- Halkın genel ekonomik ve sosyal gelişimini sağlaması

olarak sıralanırken; su toplama tesislerinin ilk yapım maliyetlerinin yüksek ve düzenli bakım gerektirmesi, tahmin edilemeyen yağış azlığ durumunda su teminin sinırlanması, bazı çatı tiplerinde kullanılan malzemeler de bulunan kimyasalların bitki sulamasında bitkilere zarar vermesi gibi dezavantajları da bulunmaktadır (16).

Gelecekte, yağmur suyunun toplanması ve tekrar kullanılması, sadece su mevcudiyetinin düşük olduğu bölgelerde değil ,aynı zamanda yılda metrekareye $1000 \mathrm{~mm}$ 'den fazla yağış alan bölgelerde de giderek önemini artırmakta olup yağmur suyunun toplanmasinın merkezi su kaynağ1 olarak görüldüğü Almanya, İtalya İspanya, Hindistan, Çin, Malezya, Kore, Japonya, Kenya, Etiyopya, Suriye, Tunus, ABD ve Kanada Brezilya, Avustralya ve Yeni Zelanda gibi dünyanın bir çok ülkesinin şehir alanlarında uygulanmaktadır (17). Nüfus artışı, doğal hidrolojik süreci değiştiren şehirleşme eğiliminin artması ve iklim değişikliği nedenlerinden dolayı artan su ihtiyacinın karşılanması, kontrolsüz akıştan kaynaklanan toprak erozyonu önlenmesi, kurak bölgelerde kirli su tüketiminden kaynaklanan sağlık sorunlarının giderilmesine katkıda bulunacak olan yağmur suyu hasadı teknolojilerinin kullanılmasinı zorunlu hale getirmektedir. Binlerce yıldır ülkemiz coğrafyasında yağmur suyu depolanip kullanılmakta olup son zamanlarda özel teşebbüs tarafından mülkiyet alanlarında yağmur suyu hasadı teknolojisiyle ilgili tesisler yapılmış olup 2017 yılında halk sağlığını ve güvenliğini, çevrenin korunmasını, içme suyu kaynaklarının taşınan suyla kirliliklerden korunmasını esas alan yağmursuyu hasadiyla ilgili tesislerin projelendirilmesi yapımı ve işletilmesiyle ilgili "Yağmur Suyu Toplama. Depolama, Deşarj Sistemleri Hakkında Yönetmelik" yasalaşarak yürürlüğe girmiştir.

\section{Türkiye'nin Su ve Enerji Durumuna Genel Bakış}

Yıllık su potansiyeli kişi başına $1700 \mathrm{~m} 3$ ' ten az olması nedeniyle Falkenmark Göstergesine göre su baskısı altında bulunan ülkemizde, yıllık ortalama $643 \mathrm{~mm} / \mathrm{m} 2$ yağ 1 ştan elde edilen 501 milyar m3 yağış suyunun \%54.69'si buharlaşırken, \%8.18'si yeraltına sızmakta, geriye kalan \%37.13'lük kısmı ise yüzey akışına geçmektedir. Yeraltından çekilebilir 14 milyar m3 ve yüzey akışından 98 milyar m3 olmak üzere toplam 112 milyar $\mathrm{m} 3$ yıllık net yeraltı ve yerüstü su potansiyelinin. (18) tüketilen 44 milyar m3'lük kısmının yaklaşık \%16'sı içme suyu (evsel kullanım), \%73 sulama, \%11 sanayide kullanılmaktadır (19).

Nüfus sayısına göre değişebilen İller Bankası içme suyu proje hazırlama teknik şartnamesinde (20) kişisel (evsel olmayan birimler hariç) evsel su tüketimi 99 ile 171 lt/kişi/gün aralığında 
olup; evsel su ihtiyacı, yerleşim yeri, konut tipi ve kullanıcıların alışkanlığına bağlı değişmekle beraber genel olarak kullanım oranları (21) Şekil 1'de aynı teknik şartnameye göre hayvansal su ihtiyacı ise Tablo 1'de görülmektedir.

Tablo 1. Hayvansal su tüketimi

\begin{tabular}{cc}
\hline Hayvan Türü & Tüketim (Lt/Adet/Gün) \\
\hline Büyük Baş Hayvan & 50 \\
Küçük Baş Hayvan & 15 \\
Tavuk Ördek Hindi & 0.25 \\
\hline
\end{tabular}

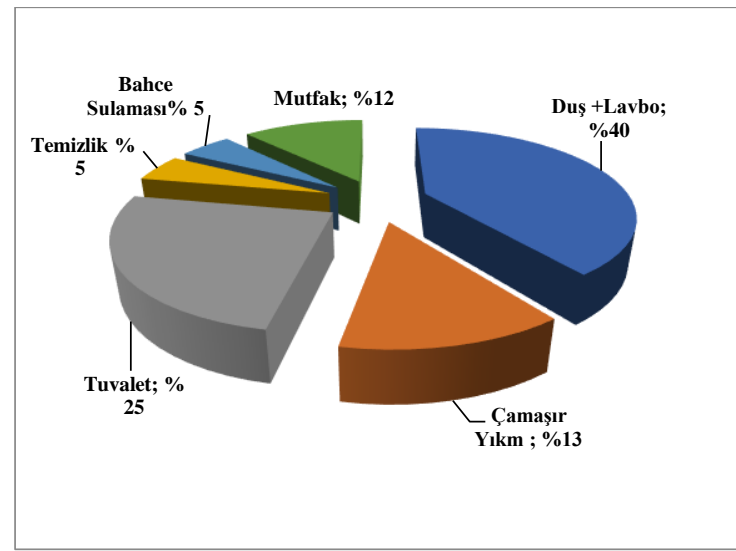

Şekil 1. Evsel su kullanım oranları

İnsanların kullanmış olduğu birçok sektöre ait ürünlerin üretimi ve alınan hizmet süreçlerinde kişi başına kullanılan su miktarı içme-kullanma amacıyla tükettiği su miktarından çok daha fazladır (22). Ülkemizde, kullanılan sanal suyun (Ürünlerin tüketildiği yerde, bu ürünün elde edilmesi sürecinde kullanılmış olan suyun da tüketildiği kabul edilmesi) su türünüm (Yeşil Mavi Gri) üretim, tüketim, ithalat ve ihracatta kullanım oranlarının belirtildiği su ayak izine göre üretim ve tüketim ayrı ayrı olmak üzere yaklaşık yılda 140 milyar m3 su kullanılmakta olup; tüketim su ayak izinin \%17 sini ise ithal edilen ürün ve hizmetlerden karşılanmaktadır (23).

Kişi başına günde ortalama 200 lt su kullanılmasına karşın kişi başına $5 \mathrm{~m} 3 /$ gün $\left(140 * 10^{9} / 365 * 79 * 10^{6} \quad\right.$ (Nüfus)) sanal su tüketiminin yaklaşık \%83'ünde yağmur suyu ve tatlı su kaynakları kullanılmaktadır (Şekil 2 ve 3). Ülkemizde en iyimser yaklaşımla 23.80 milyar TL $(140 * 109 * 0.17 * 1$ (Su fiyat 1 $\mathrm{TL} / \mathrm{m} 3)$ ) ithal alınan ürün ve hizmetlere karşılık sanal su ödemesi yapılmakta; bu nedenle teknolojik ürün üretmek şartıyla kişisel ithal ürün kullanma alışkanlıkları ve tercih nedenlerinin tespitinin yanı sira su tasarrufu ve yağmur suyundan maksimum verimi elde edilmesi hakkında araştırmaların artırılması su baskısı alında bulunan ülkemizde zorunlu hale gelmektedir.

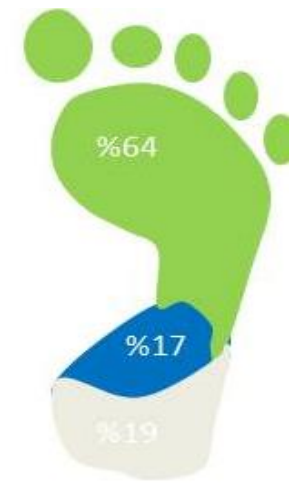

Şekil 2. Üretim su ayak izi [23]

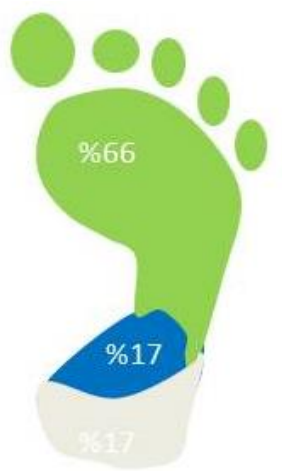

Şekil 3. Tüketim su ayak izi [23]

Ülkemizin elektrik sistemlerinin kurulu gücünün yaklaşı \% \%2.70'sinde ithal kaynaklarla elektrik üretilmekte olup (24); 2017 y1lında üretilen $297277.50 \mathrm{GWh}$ elektrik enerjisinde \% 45.20'sinde yerli, \% 54.80'inde ithal kaynak kullanılmıştır (25). Toplam üretilen elektrik enerjisine ikinci sırada katkıda bulunan hidrolik kaynaklar, yerli kaynaklı enerji üretiminde $\% 55$ 'lik oranla ilk siradadır (Tablo 2). 
Tablo 2. Elektrik enerjisi üretiminin kaynaklara göre dağılımı (2017)

\begin{tabular}{lcc}
\hline \multicolumn{1}{c}{ KAYNAK } & $\begin{array}{c}\text { ÜRETIM } \\
(\mathbf{G W h})\end{array}$ & KATKISI (\%) \\
\hline İthal Kömür & 51118.10 & 17.20 \\
Taşkömürü+Asfaltit & 5663.80 & 1.91 \\
Linyit & 40694.40 & 13.69 \\
Doğal Gaz & 110490.00 & 37.17 \\
Sıvı Yakıtlar & 1199.90 & 0.40 \\
Barajlı & 41312.60 & 13.90 \\
D.Göl ve Akarsu & 16905.90 & 5.69 \\
Rüzgâr & 17903.80 & 6.02 \\
Yenilenebilir & 2124.00 & 0.71 \\
Atık+Atık Isı & 848.30 & 0.29 \\
Atık Isı & 6127.50 & 2.06 \\
Jeotermal & 2889.30 & 0.97 \\
Güneş & $\mathbf{2 9 7 2 7 7 . 5 0}$ & $\mathbf{1 0 0 . 0 0}$ \\
\hline TOPLAM & & \\
\hline
\end{tabular}

Teorik olarak yılda 433000 GWh hidroelektrik üretme potansiyeline sahip ülkemizin, hidrolik kaynakları günümüz teknik koşullarına göre y1lda $216000 \mathrm{GWh}$, ekonomik olarak ise $158000 \mathrm{GWh}$ elektrik üretme potansiyeline sahip olup; mevcut işletmelerden ekonomik potansiyelin sadece \%60'1 olan $95241 \mathrm{GWh}$ elektrik enerjisi üretilmektedir (26). Türkiye'nin teknik hidrolik potansiyelinin \%15'ini, Tablo 3'de güçlerine göre sinıflandırmaları verilen küçük, mini, çok küçük (mikro) ve en küçük (piko) hidroelektrik santrallerden karşılanabileceği yapılan çalışmalarda tespit edilmiştir (27).

Tablo 3. HES'lerin güçlerine göre sınıflandırılması

\begin{tabular}{lc}
\hline \multicolumn{1}{c}{ Sınıfı } & Güç (kW) \\
\hline Büyük HES & $>100,000$ \\
Orta HES & $10,000-100,000$ \\
Küçük HES & $1,000-10,000$ \\
Mini HES & $100-1,000$ \\
Çok Küçük 5-100 & $5-100$ \\
Piko & $0-5$ \\
\hline
\end{tabular}

Ülkemizin kişi başına yıllık ortalama 3400

KWh tüketim ile Avrupa ortalamasının altında bulunması, artan nüfus artışı, fosil yakıtların gün geçtikçe tükenmesi ve maliyetlerinin artması sebebiyle yerli kaynak olan hidrolik güçten maksimum seviyede yararlanmayı gerektirmekte; bu nedenle karayollarında yağmur suyu hasadıyla çok küçük hidroelektrik santrallerle elektrik üretimi çalışmalarının yapılması teorik hidroelektrik potansiyelinden yararlanmaya katkıda bulunacaktır.

\section{Materyal ve Yöntem}

\section{Metodoloji}

Bingöl şehir merkezine yakın devlet yollarımın Google Earth'den yatay ve düşey eksenleri incelenerek, güzergahların yağmur suyu hasadı kapasitesi ile toplanan yağmur suyunun depolanarak cazibeli olarak akışın sağlanması durumunda hidroelektrik potansiyeli tespit edilmeye çalışılmıştır.

\section{Çalışma Alanı}

Fırat Havzası içerisinde bulunan Bingöl ilinde Karayolları Genel Müdürlüğünün sorumluluğunda $224 \mathrm{~km}$ devlet yolunun (Şekil4), bu çalışma kapsamında Kuruca GeçitiBingöl (Gayıt Köprüsü), Karlıva, Ilıcalar Solhan Ayrım-Bingöl (Gayıt Köprüsü) „Karlıova Ayr-Solhan güzergâhlarının il merkezine yakın ve cazibeli akışa uygun olan bazı kisımlarının Google Earth hataları dâhilinde düşey eksen profili tespit edilmiş (Şekil-5); Kurudere mevkisi başlangıç alınarak kot, kilometre ve ilin 1961-2018 y1lları aras1 yıllık yağış ortalamasına göre yol kaplama yüzeyinden araziye akıș olmadan toplanacak (hasat) yağmur suyu miktarlarının krokisi Şekil 6'da gösterilmiştir.

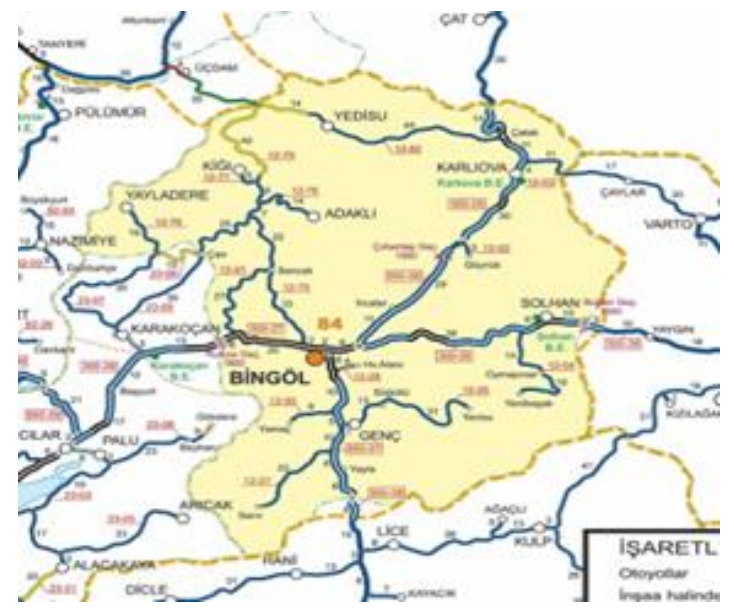

Şekil 4. KGM Bingöl ili Yol Haritast 

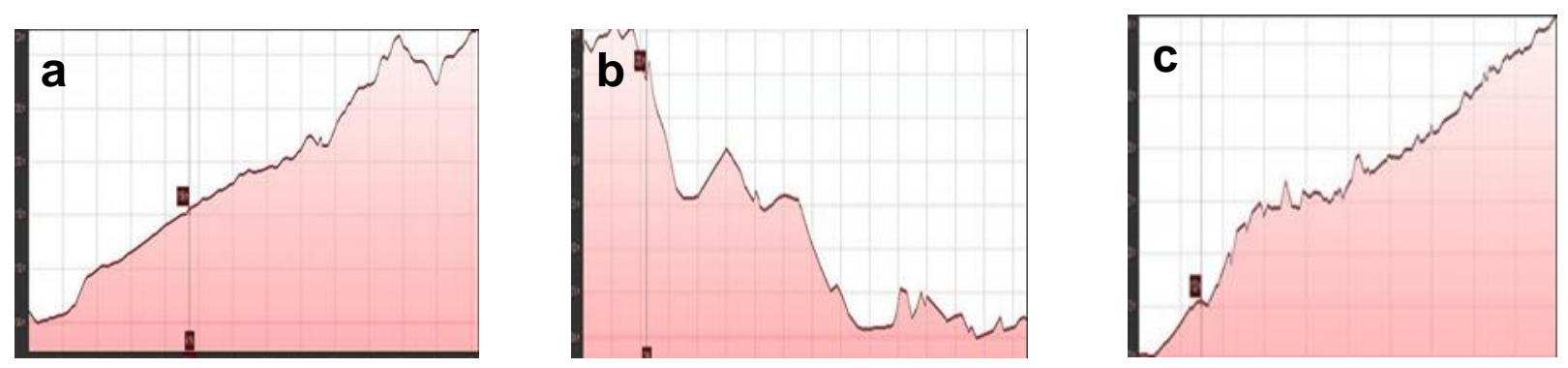

Şekil 5. a) Bingöl (Gayıt Köprüsü) -Kurudere 9,85 km (Kuruca Geçidi-Bingöl (Gayıt Köp 32 km), b) Ilıcalar-Bingöl (Gayıt Köp), 15,50km (Karlıova, Ilıcalar-Bingöl (Gayıt Köp 65 km ), c) Karlıova Ayr-Solhan 24940km (Karliova Ayr-Solhan 46 km)

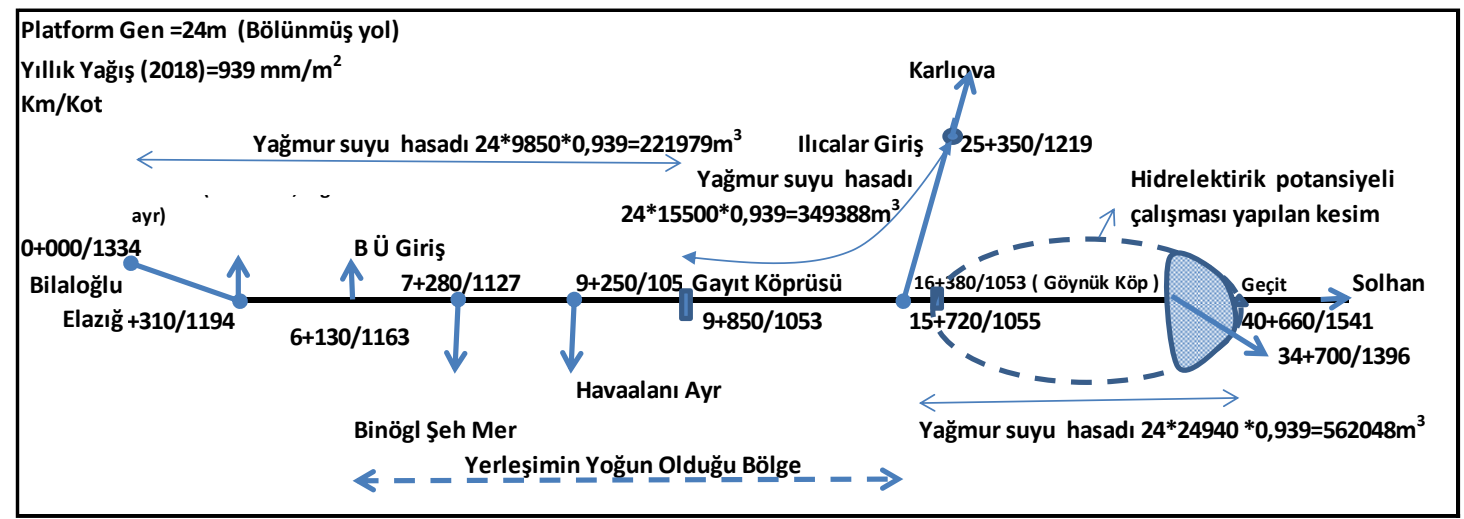

Şekil 6. Bingöl ilinde yă̆mur suyu hasadı çalışması yapılan güzergâhlar

Hidroelektrik potansiyeli, debi ve düşü yüksekliği önemli derecede etkilediğinden yol kaplama yüzeyinden yağmur suyu hasadı yapılarak belli bir miktar suyun depolanması ve belli bir düşü yüksekliğinden getirilerek mini veya piko santrallerle hidroelektrik enerji üretilmesi açısından Karlıva Ayr-Solhan güzergahı uygun olduğundan kilometre 34+700-40+660 arası yüzeysel akış katsayısı 0.9 kabul edilerek; Şekil 7'de gösterilen yatay eksen geometrisi ve meteorolojik verilere göre yağmur suyunun yol en kesiti üzerinde toplanacağı kesimleri ve aylık miktarları Tablo 4'te aylık miktarlara göre kanalların minimum kesit alanları Tablo 5'te gösterilmiştir.

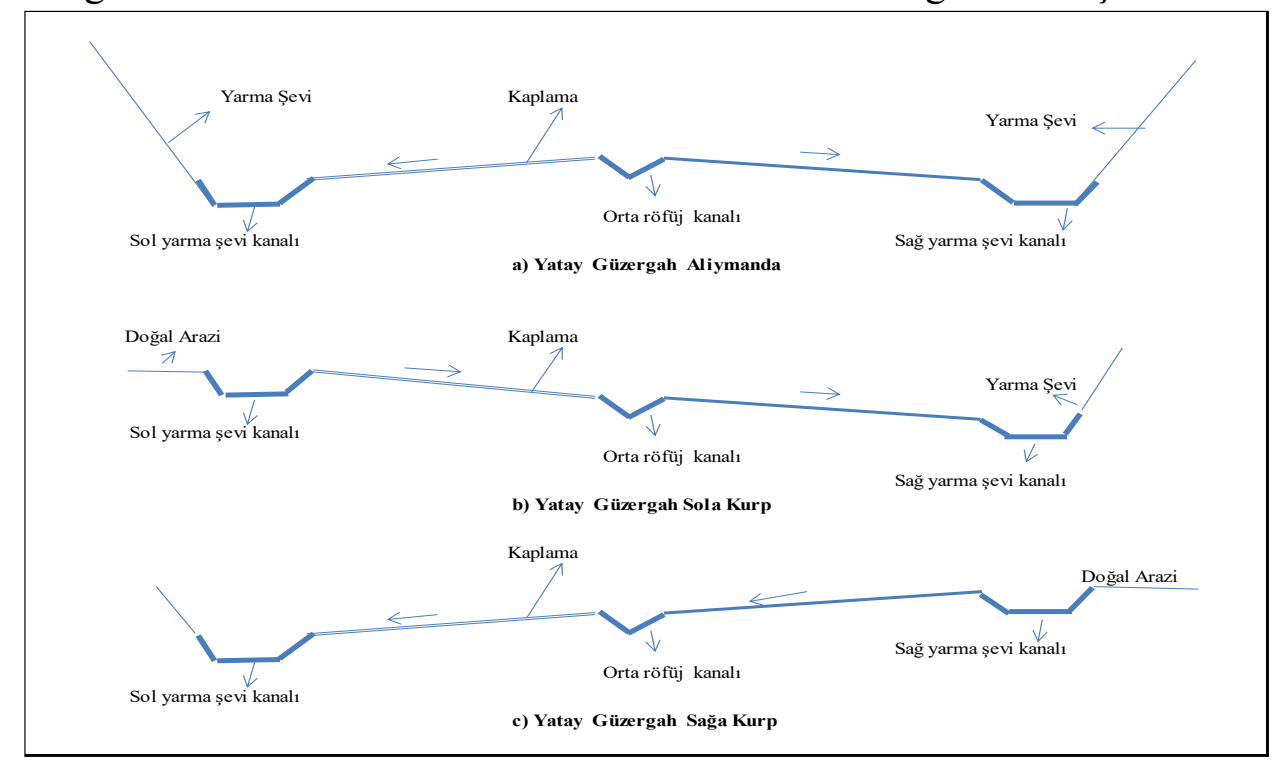

Şekil 7. Yol Yüzeyinde Yağmur Suyu Toplanacak Kanallar 
Tablo 4. Yıllık yağış ortalamasına göre Karlıva Ayr-Solhan güzergahında (34+700-40+660) kanallarda toplanacak yağmur suyu miktarları

\begin{tabular}{|c|c|c|c|c|c|c|c|}
\hline \multirow{3}{*}{ Kilometre } & \multirow{3}{*}{$\begin{array}{c}\text { Ara } \\
\text { Mesafe } \\
\text {-A(m) }\end{array}$} & \multirow{2}{*}{\multicolumn{2}{|c|}{ Kot }} & \multirow{3}{*}{$\begin{array}{c}\text { Yatay } \\
\text { Güz Tip }\end{array}$} & \multicolumn{3}{|c|}{ Kanalda Toplanan $\mathrm{Su}\left(\mathrm{m}^{3}\right)$} \\
\hline & & & & & \multirow{2}{*}{$\begin{array}{c}\text { Sağ Ban Kan } \\
\left(\mathbf{A} * \mathbf{P g} / 2 * C^{*} \mathbf{Y}\right)\end{array}$} & \multirow{2}{*}{$\begin{array}{c}\text { Orta Röfüj Kan } \\
(\mathrm{A} * \operatorname{Pg} / 2 * \mathbf{C} * \mathbf{Y})\end{array}$} & \multirow{2}{*}{$\begin{array}{r}\text { Sol Ban Kan } \\
\left(\mathrm{A}^{*} \mathrm{Pg} / \mathbf{2}^{*} \mathrm{C}^{*} \mathbf{Y}\right.\end{array}$} \\
\hline & & Baş. & Bit. & & & & \\
\hline $34+700-35+840$ & 1140 & 1396 & 1435 & Aliyman & 11567.124 & & 11567.124 \\
\hline $35+840-36+530$ & 690 & 1435 & 1449 & Saga & 7001.154 & 7001.154 & \\
\hline $36+530-37+210$ & 680 & 1449 & 1461 & Sola & & 6899.688 & 6899.688 \\
\hline $37+210-38+000$ & 790 & 1461 & 1483 & Saga & 8015.814 & 8015.814 & \\
\hline $38+000-38+370$ & 370 & 1483 & 1490 & Sola & & 3754.242 & 3754.242 \\
\hline $38370-40+510$ & 2140 & 1490 & 1535 & Aliyman & 21713.724 & & 21713.724 \\
\hline $40+510-40+660$ & 150 & 1535 & 1541 & Sağs & 1521.99 & 1521.99 & \\
\hline TOPLAM & 5960 & -- & --- & --- & 49819.806 & 27192.888 & 43934.778 \\
\hline
\end{tabular}

Platform Gen $\mathrm{Pg}=24$ :Yüzey akış katsayısı $\mathrm{C}=0,9$ :Yı1lık yağış ort. $\mathrm{Y}=939,50 \mathrm{~mm} / \mathrm{m}^{2}$

Yağmur suyu toplanan; Sağ kanal boyu LSg=4910m, Orta kanal boyu LO=2680 m Sol kanal boyu LSl=4330m

Tablo 5. Aylık yağış ortalamasına göre kanallarda toplanacak yağmur suyu miktarları ve kesit alanları

\begin{tabular}{|c|c|c|c|c|c|c|c|}
\hline \multirow[b]{2}{*}{ Ay } & \multirow[b]{2}{*}{$\underset{\left(\mathbf{m m} / \mathbf{m}^{2}\right)}{\text { Yağıș }}$} & \multicolumn{3}{|c|}{ Aylık Su Birikme Miktarlar $\left(\mathrm{m}^{3}\right)$} & \multicolumn{3}{|c|}{$\begin{array}{c}\text { Aylık Yağışa Göre Gerekli Min Kesit Alanı } \\
\left(\mathrm{m}^{2}\right)\end{array}$} \\
\hline & & $\begin{array}{c}\text { Sağ Ban Kan } \\
(\mathrm{SgA}=\mathrm{SgKT} * \\
\text { Ya/Y) }\end{array}$ & $\begin{array}{c}\text { Orta Röf Kan } \\
(\text { OKA }=\text { OKT } \\
\text { Ya/Y) }\end{array}$ & $\begin{array}{c}\text { Sol Ban Kan } \\
(\mathrm{SIA}=\mathrm{SIKT} * \\
\text { Ya/Y) }\end{array}$ & $\begin{array}{c}\text { Sağ Ban } \\
\text { Kan } \\
\text { (SgA/LSğ) }\end{array}$ & $\begin{array}{c}\text { Orta Röf } \\
\text { Kan } \\
\text { (OKA/LO) }\end{array}$ & $\begin{array}{l}\text { Sol Ban Kan } \\
\text { (SlA/LSI) }\end{array}$ \\
\hline Kasım & 107.7 & 5711.12 & 3117.27 & 5036.48 & 1.16 & 1.16 & 1.16 \\
\hline Aralık & 133.6 & 7084.54 & 3866.92 & 6247.67 & 1.44 & 1.44 & 1.44 \\
\hline Ocak & 137.2 & 7275.44 & 3971.12 & 6416.02 & 1.48 & 1.48 & 1.48 \\
\hline Şubat & 132.9 & 7047.42 & 3846.66 & 6214.94 & 1.44 & 1.44 & 1.44 \\
\hline Mart & 128.5 & 6814.10 & 3719.30 & 6009.17 & 1.39 & 1.39 & 1.39 \\
\hline Nisan & 117.5 & 6230.79 & 3400.92 & 5494.77 & 1.27 & 1.27 & 1.27 \\
\hline Mayıs & 74.8 & 3966.49 & 2165.01 & 3497.95 & 0.81 & 0.81 & 0.81 \\
\hline Haziran & 21.1 & 1118.89 & 610.72 & 986.72 & 0.23 & 0.23 & 0.23 \\
\hline Temmuz & 5.5 & 291.65 & 159.19 & 257.20 & 0.06 & 0.06 & 0.06 \\
\hline Ağostos & 3.2 & 169.69 & 92.62 & 149.64 & 0.03 & 0.03 & 0.03 \\
\hline Eylül & 11.5 & 609.82 & 332.86 & 537.79 & 0.12 & 0.12 & 0.12 \\
\hline Ekim & 66 & 3499.85 & 1910.30 & 3086.42 & 0.71 & 0.71 & 0.71 \\
\hline TOPLAM & 939.5 & 49819.81 & 27192.888 & 43934.778 & 10.15 & 10.15 & 10.15 \\
\hline
\end{tabular}

Kanal dip kotlarının kaplama banket (yatay eksene göre değişebilen banket kotları bu çalışmada yol eksen kotları alınmıştır) kotlarından trafik güvenliği acısından $75 \mathrm{~cm}$ aşağıda olması gerektiğinden tespit edilen yol eksen kotlarından $75 \mathrm{~cm}$ çıkarılarak sol kanal kotları hesaplanmış (Tablo 6) buna göre kanal düşey eksen hattı çizilmiştir. Kanalda toplanan suları (34700-40+660) depolanması don derinliği de göz önüne alınarak kilometre 40+660'da kanal dip kotundan 1.50 m aşağısından 
başlanarak ve cazibeli akışa uygun olarak depolama borularının kotları tespit edilerek (Tablo 7) düşey ekseni Şekil 8'de gösterilmiştir.

Tablo 6. Sol Kanal Kotları (344700-40+660)

\begin{tabular}{cccccccc}
\hline KM & KOT & KM & KOT & KM & KOT & KM & KOT \\
\hline $34+700$ & 1395.25 & $36+200$ & 1441.25 & $37+210$ & 1461.25 & $38+421$ & 1488.25 \\
$35+141$ & 1419.25 & $36+370$ & 1458.25 & $37+450$ & 1475.25 & $38+617$ & 1485.25 \\
$35+303$ & 1415.25 & $36+520$ & 1447.25 & $37+500$ & 1476.25 & $38+885$ & 1493.25 \\
$35+459$ & 1424.25 & $36+640$ & 1466.25 & $37+670$ & 1482.25 & $38+983$ & 1491.25 \\
$35+562$ & 1423.25 & $36+780$ & 1461.25 & $37+850$ & 1478.25 & $39+560$ & 1518.25 \\
$35+860$ & 1436.25 & $36+890$ & 1468.25 & $38+060$ & 1484.25 & $39+850$ & 1513.25 \\
$35+940$ & 1435.25 & $36+950$ & 1462.25 & $38+270$ & 1487.25 & $40+490$ & 1527.25 \\
$36+030$ & 1439.25 & $36+990$ & 1465.25 & $38+370$ & 1486.25 & $40+660$ & 1540.25 \\
\hline
\end{tabular}

Tablo 7. Sol depolama boru kotları (34+700-40+660)

\begin{tabular}{cccccccc}
\hline KM & KOT & KM & KOT & KM & KOT & KM & KOT \\
\hline $40+660$ & 1538.75 & $38+421$ & 1483.25 & $37+210$ & 1459.75 & $35+940$ & 1433.75 \\
$40+490$ & 1525.75 & $38+370$ & 1483.15 & $36+990$ & 1459.5 & $35+860$ & 1433.5 \\
$39+850$ & 1511.75 & $38+270$ & 1482.95 & $36+780$ & 1459.25 & $35+562$ & 1421.75 \\
$39+560$ & 1511.25 & $38+060$ & 1482.75 & $36+520$ & 1445.75 & $35+459$ & 1421.45 \\
$38+983$ & 1489.75 & $37+850$ & 1476.75 & $36+370$ & 1445.5 & $35+303$ & 1413.75 \\
$38+885$ & 1489.25 & $37+670$ & 1476.25 & $36+200$ & 1439.75 & $35+141$ & 1413.5 \\
$38+617$ & 1483.75 & $37+500$ & 1474.75 & $36+030$ & 1437.75 & $34+700$ & 1393.75 \\
\hline
\end{tabular}

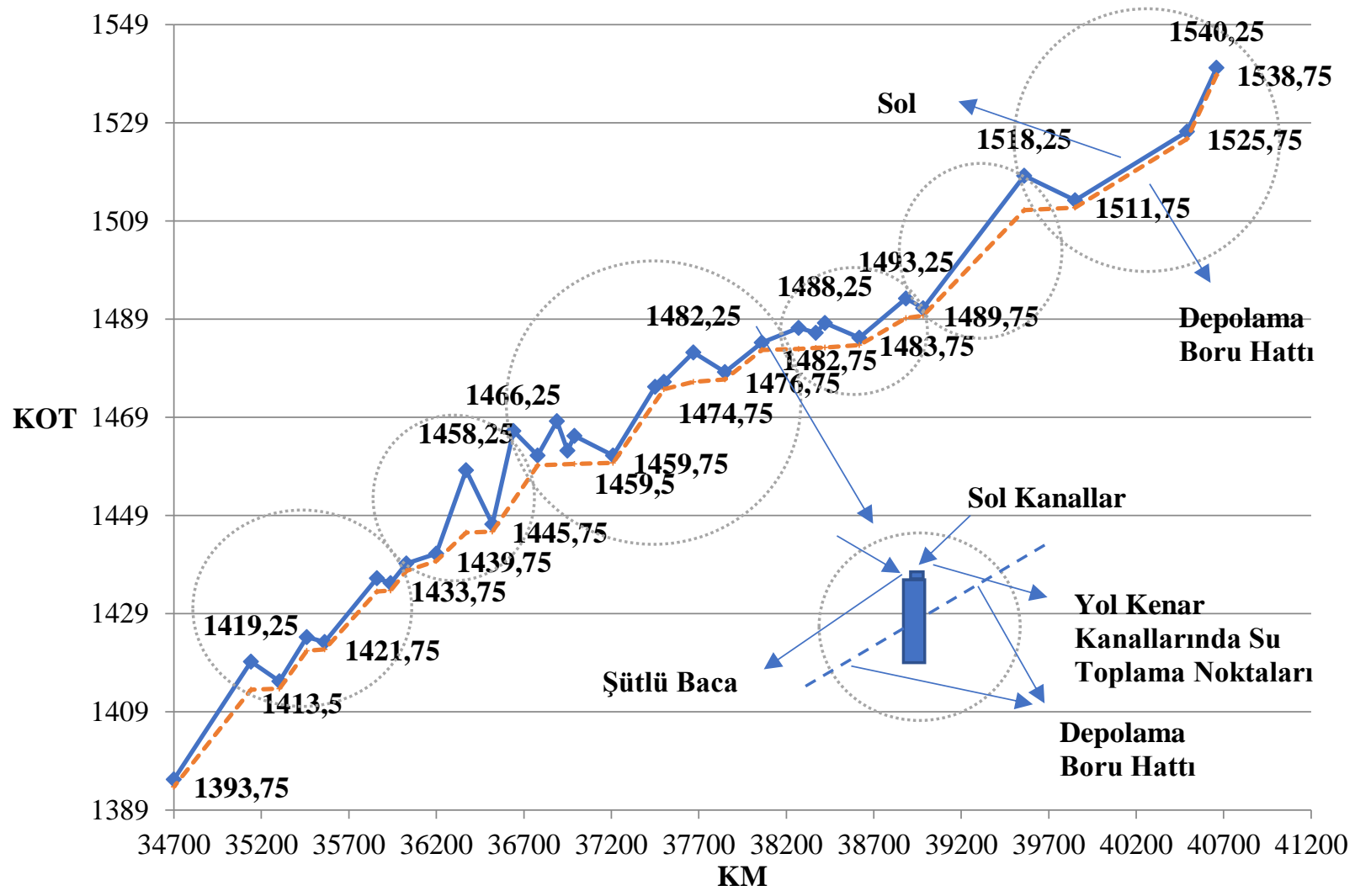

Şekil 8. Sol açık kanal ve depolama borusu düşey ekseni 
Karayolları tasarım ilkelerine göre rakımı 900 metreden yukarı olan kotlarda ve kar yağışının yoğun olduğu bölgelerde yarma en kesitlerinin banket kenarlarında uygulanan trapez kesitin alanı (Şekil 9 ve 10) meteorolojik verilere göre don olaylarının yaşandığı Aralık Ocak ve Şubat aylarının toplamı için gerekli olan $4.72 \mathrm{~m} 2$ $(1.44+1.48+1.44)$ olması ayrıca buharlaşmanın en fazla olduğu Haziran Temmuz Ağustos ayları içerisinde en büyük değere sahip olan Haziran ay1 değeri olan $0.23 \mathrm{~m} 2$ kesit alanı için $600 \mathrm{~mm}$ çaplı depolama borusu seçiminin maksimum seviyede yağmur suyu hidroelektrik potansiyelinden yararlanmasını sağlayacaktır.

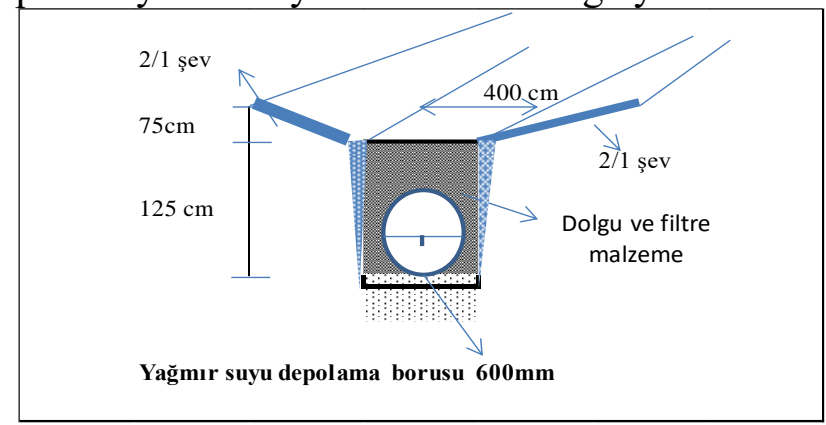

Şekil 9. Açık kanal ve depolama borusu en kesiti $(40+660-34+700)$

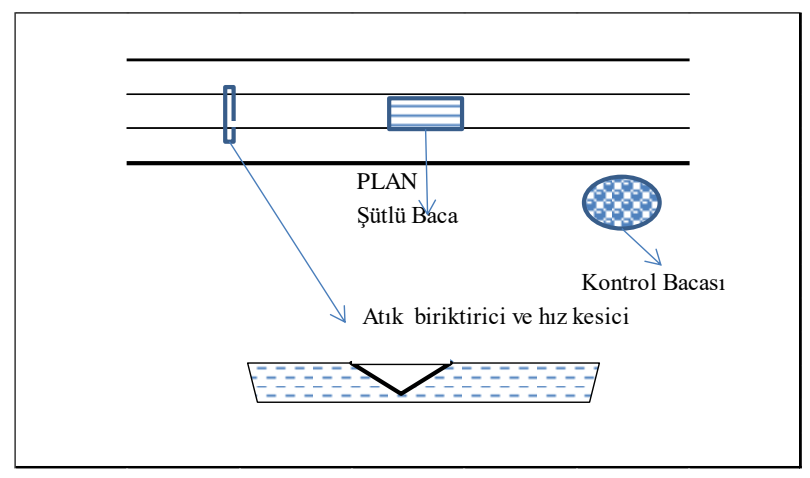

Şekil 10. Açık kanal plan krokisi
Kilometre 40+660-34+700 aras1 yol en kesitinin solunda depolama borularında toplanan yağmur sular1 Kilometre $34+700-16+380$ (Göynük Köprüsü) aras1 tespit edilen yol kenar kotlarından $2 \mathrm{~m}$ (Kanal yüksekliği $0.75 \mathrm{~m}+$ boru ve boru üstüne gelecek malzeme $1.25 \mathrm{~m}$ ) düşünülerek cazibeli akışa uygun kotlar tespit edilerek (Tablo-8); cebire boru hattının düşey ekseni ve yük kaybı çizilmiştir (Şekil 11).

Tablo 8. Cebire boru kotları

\begin{tabular}{cccccc}
\hline KM & KOT & KM & KOT & KM & KOT \\
\hline $16+380$ & 1053 & $24+180$ & 1264 & $28+880$ & 1339 \\
$19+080$ & 1128 & $24+470$ & 1301 & $29+180$ & 1315 \\
$19+750$ & 1125 & $24+850$ & 1266 & $30+880$ & 1344 \\
$21+100$ & 1197 & $25+330$ & 1264 & $31+580$ & 1339 \\
$22+120$ & 1241 & $25+450$ & 1288 & $32+480$ & 1360 \\
$22+880$ & 1270 & $27+180$ & 1274 & $33+780$ & 1382 \\
$23+120$ & 1253 & $27+380$ & 1286 & $34+200$ & 1387 \\
$23+450$ & 1267 & $28+180$ & 1279 & $34+700$ & 1393.75 \\
\hline
\end{tabular}




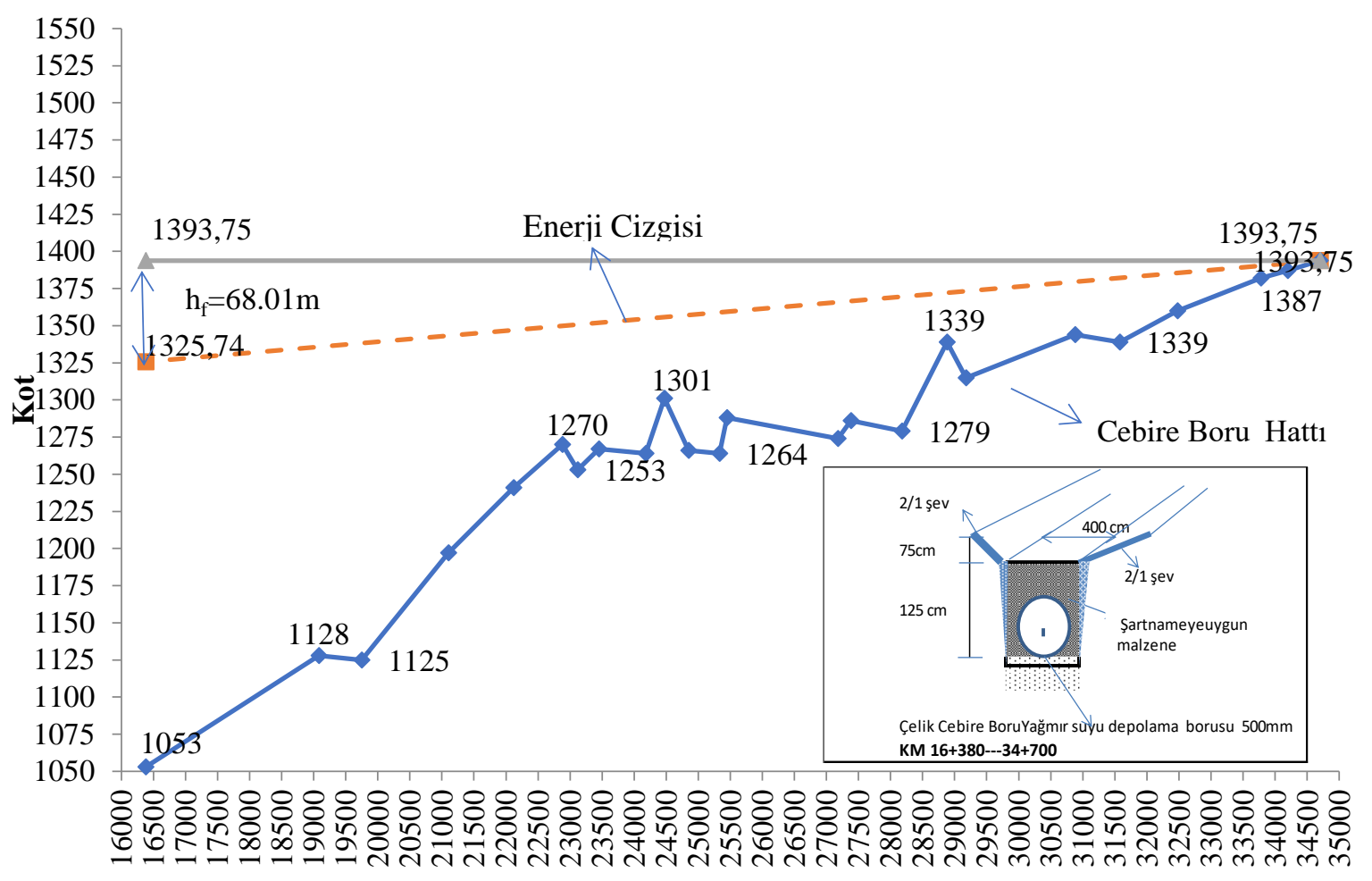

$\mathbf{K m}$

Şekil 11. Cebire Boru Düşey ekseni Enerji Çizgisi

Çelik cebire borularla depolanan suyun km 16+380'de deşarj edilerek enerji üretimi DarcyWeisbach Swamee-Jai eşitlikleri (Denklem 2, 3 ve 4, ) kullanılarak hesaplanmıştır.

$Q=A . V$

$R_{e}=\frac{V . D}{v}$

$f=0.25\left[\log \left(\frac{\varepsilon / D}{3.7}+\frac{5.74}{R e^{0.9}}\right)\right]^{-2}$

$h_{f}=\mathrm{f} \frac{L \cdot V^{2}}{2 \cdot g \cdot D}$

$N_{T R}=13.3 Q H e_{T R}$

$E=Q \cdot H \cdot g \cdot \gamma \cdot e_{, j}, e_{t \cdot} \cdot e_{T R} \cdot t$

Eşitliklerde Q debi $\left(\mathrm{m}^{3} / \mathrm{s}\right)$, A boru kesit alanı $\left(\mathrm{m}^{2}\right), \mathrm{V}$ hiz $(\mathrm{m} / \mathrm{s}), v$ suyun kinematik viskozite $\left(\mathrm{m}^{2} / \mathrm{s}\right), f$ Darcy-Weisbach sürtünme katsayısı, $\varepsilon$ boru pürüzlük katsayısı, D boru çapı (m) Re Reynold Katsayısı, h yükseklik kaybı (m) L boru hattı uzunluğu (m), g yerçekimi ivmesi $\left(\mathrm{m} / \mathrm{s}^{2}\right) \mathrm{H}$ düşü yüksekliği (m), N TR türbün gücü (BG) $\mathrm{e}_{\mathrm{TR}}$ türbin verimi $\mathrm{E}$ üretilecek enerji (Wattsaat), $e_{j}$ jeneratör verimi, $e_{t}$ transformatör verimi, $\gamma$ suyun yoğunluğu $\left(1000 \mathrm{~kg} / \mathrm{m}^{3}\right), \mathrm{t}$ zaman (sa) dir.
$\mathrm{Q}=0.2 \mathrm{~m}^{3} / \mathrm{s} \mathrm{V}=1 \mathrm{~m} / \mathrm{s}$ ve $\mathrm{v}=1.36 * 10^{-6} \mathrm{~m}^{2} / \mathrm{s} \mathrm{kabul}$ edilerek, çelik boru pürüzlük katsayısı $\varepsilon=0,0045$ seçilmesi durumunda

$$
\begin{gathered}
D=\sqrt{4 * 0,2 / 1 . \pi}=0.504 \mathrm{~m} \text { seçilen } 0.50 \mathrm{~m} \\
R e=\frac{1 . .0,5}{1,36.10-6}=371048,90 \\
f=0.25\left[\log \left(\frac{0,0045 / 0,5}{3.7}+\frac{5.74}{371048,90^{0.9}}\right)\right]^{-2}=0,0367 \\
h_{f}=0,0367 \frac{L(34700-16380) \cdot 1^{2}}{2.9 .81 .0,50}=68,01 \mathrm{~m}
\end{gathered}
$$

Kasım ayında toplanan su miktarı= $5711.12+3117.27+5036.48=13864.87 \mathrm{~m}^{3}$

Kasım ayında toplanan suyun $0.20 \mathrm{~m}^{3} / \mathrm{sn}$ debiyle deşarj süresi $=13864.87 /(0.20 * 3600)=19.25 \mathrm{sa}$ $\mathrm{e}_{\mathrm{TR}}=0.90, \quad \mathrm{e}_{\mathrm{j}}=0.98, \quad \mathrm{e}_{\mathrm{t}}=0.95$ kabul edilmesi durumunda

$\mathrm{N}_{\mathrm{TR}}=13.3 * 0,2 *(1396-1053-68.01) * 0.90$

$=658.33 \mathrm{BG}$

$\mathrm{E}$

$=0.2 *(1396-1053-$

$68.01) * 9.81 * 1000 * 0.90 * 0.98 * 0.95 * 19.25$

$=8702395.73 \mathrm{Watt}$ 
Kasım ayı için enerji üretimi hesaplamaları yılın diğer ayları içinde yapılarak ;yılda türbinin 167.98 sa çalışarak 75.940.314,85 Watt enerji üretileceği hesaplanmıştır (Tablo 9).

Tablo 9. Aylara göre enerji üretimi

\begin{tabular}{cccccc}
\hline Ay & $\begin{array}{c}\text { Yağıs } \\
\left(\mathbf{m m} / \mathbf{m}^{\mathbf{2}}\right)\end{array}$ & $\begin{array}{c}\text { Kanal Top } \\
\mathbf{S u}\left(\mathbf{m}^{\mathbf{3}}\right)\end{array}$ & $\begin{array}{c}\text { Aylık } \\
\text { Çalışma } \\
\text { Süresi }(\mathbf{S a})\end{array}$ & $\begin{array}{c}\text { Enerji Verimi } \\
(\mathbf{0 . 9} * \mathbf{0 . 9 8} * \mathbf{0 . 9 5}=\mathbf{0 . 8 3 7 9})\end{array}$ & $\begin{array}{c}\text { Aylık Enerji Üretimi E } \\
(\mathbf{W a t t})\end{array}$ \\
\hline Kasım & 107.7 & 13864.87 & 19.25 & 0.8379 & 8702395.73 \\
Aralık & 133.6 & 17199.13 & 23.89 & 0.8379 & 10798963.35 \\
Ocak & 137.2 & 17662.58 & 24.53 & 0.8379 & 11089953.38 \\
Şubat & 132.9 & 17109.01 & 23.76 & 0.8379 & 10742381.95 \\
Mart & 128.5 & 16542.58 & 22.98 & 0.8379 & 10386727.47 \\
Nisan & 117.5 & 15126.48 & 21.01 & 0.8379 & 9497591.27 \\
Mayıs & 74.8 & 9629.45 & 13.37 & 0.8379 & 6046126.18 \\
Haziran & 21.1 & 2716.33 & 3.77 & 0.8379 & 1705524.90 \\
Temmuz & 5.5 & 708.05 & 0.98 & 0.8379 & 444568.10 \\
Ăgostos & 3.2 & 411.96 & 0.57 & 0.8379 & 258657.80 \\
Eylül & 11.5 & 1480.46 & 2.06 & 0.8379 & 929551.49 \\
Ekim & 66 & 8496.58 & 11.80 & 0.8379 & 5334817.22 \\
\hline TOPLAM & $\mathbf{9 3 9 . 5}$ & $\mathbf{1 2 0 9 4 7 . 4 7}$ & $\mathbf{1 6 7 . 9 8}$ & $\mathbf{0 . 8 3 7 9}$ & $\mathbf{7 5 9 4 0 3 1 4 . 8 5}$ \\
\hline
\end{tabular}

Üretilen enerjinin Bingöl ili için y1llık

yaklaşık tutarı 17466TL $\quad(0.23$

TL/kwh)*75940.314)dir.

\section{Sonuçlar ve Tartışma}

Bingöl ilinin Şehir merkezine yakın devlet yollarında yağmur suyu hasadı yöntemi ile toplanan suyun cazibeli olarak akıtılması durumunda;

- $\quad$ Yilda $5960 \mathrm{~m}$ bölünmüş yoldan toplanan yağmur suyundan cazibeli akışla üretilen $75,940,314.85$ Watt elektrik enerjinin yaklaşık olarak y1llık $22(75940 / 3400)$ kişinin enerjisini karşılayabildiğinden; depolama, cebire boru ve bu borular için yapılacak kazı dolgu ve yatay sondaj imalat maliyetleri göz önüne alındığında üretilen enerjinin ekonomik olmamasına karşın bu tür projelerin sayısının artırılması enerji ihtiyacı olan ülkemizin elektrik enerji üretiminin miktarını artıracağı,

- Günlük kiși başına 170 lt evsel su kullanımının \%30'u bahçe ve tuvalet ihtiyaçlarında kullanılmakta olup; Bingöl (Gayıt Köprüsü)-Kurudere, Ilıcalar-Bingöl (Gayıt Köprüsü), Karlıva Ayr-Solhan güzergahlarının cazibeli akışa uygun şehir merkezine yakın 50.290 kilometrelik kısmlarından yağmur suyu hasad1 ile toplanan $1133415 \quad \mathrm{~m} 3$ $(221979+562048+349388)$ suyun filitrasyon yapılarak kullanılması durumunda 51754 $(1133415 /(0.2 * 0.30 * 365)$ kişinin y1llık bahçe ve tuvalet suyu ihtiyacını karşılayabileceği gibi normal isale hatların pompa işletme masraflarına göre pompa işletme masraflarının düşüreceği,

- Karayolları Genel Müdürlüğünce yapılan Karayolu Projelerinde yatay, düşey ve yerleşim bölgelerine yakınlığı göz önünde bulundurularak yağmur suyu hasadı projelerinin hazırlanması su baskisı altında bulunan Ülkemizin su kaynaklarına katkıda bulunacağı ayrıca depolanan suların karayolları yakınında bulunan tarım arazilerinin sulanmasinda ve kullanılabileceği tespit edilmiştir.

\section{Kaynaklar}

1. The Global Risks Report 2018, World Economic Forum, 13th Edition, Geneva. http://www3.weforum.org/docs/WEF_GRR18_R eport.pdf.

2. Global Water Framework, 2012, 6th World Water Forum, Marseille, France, 12-17 March, http://www.worldwatercouncil.org/sites/default/fi les/2017-10/6th_world_water_forum. 
3. Final Report, 2015, 7th World Water Forum, Daegu and Gyeongju, Republic of Korea, http://www.worldwatercouncil.org/sites/default/fi les/2017.

4. M., Yeniçeri, 2018, Yağmur Sularının Hasadı ve Aktif Olarak Tarımsal Sulamada Kullanılması, Afet ve Risk Dergisi, 1(2), 126-136.

5. V., Notaro, L., Liuzzo, G., Freni, 2016, Reliability Analysis of Rainwater Harvesting Systems in Southern Italy, Procedia Engineering, 162, 373380.

6. M., Dakua, A., M., Redwan, B., N., Jahan, S., M., Tareq, S., Ahmed, N., F., Noor, 2016, A Case Study on Management of Rainwater Reservoir Areas In Hilly of Bangladesh, International Journal of Civil Engineering and Technology (IJCIET), 7, 6, 193-201.

7. J., Zhi-yun, L., Xiao-yan, M, Yu-jun, 2013, Water and Energy Conservation of Rainwater Harvesting System in the Loess Plateau of China, Joururnal of Integrative Agriculture, 12(8), 13891395

8.https://web.wpi.edu/Pubs/E-project/Available/Eproject-032118-

144002/unrestricted/Rainwater_Energy_Harvesti ng_MQP_Final.pdf, Energy Harvesting from Rainwater, Worcester Polytechnic Institute.

9. A., S., Vieira, C., D., Beal, E., Ghisi, R., A., Stewart, 2014, Energy intensity of rainwater harvesting systems A review, Renewable and Sustainable Energy Reviews, 34, 225-242.

10.https://www.samsamwater.com/library/Book6_W ater_from_roads.pdf, Water from Roads A handbook for technicians and farmers on harvesting rainwater from roads, Danish International Development Assistance (Danida) 2006.

11. S., N., Sachdeva, U., Sharma, 2008, Potential of Road Rainwater Harvesting in Urban Areas, 3rd IASME/WSEAS Int. Conf. on Water Resources, Hydraulics \& Hydrology (WHH '08), University of Cambridge, UK, Feb. 23-25.

12. B., T., Meriç, 2004, Su Kaynakları Yönetimi ve Türkiye, Jeoloji Mühendisliği Dergisi, 28(1), 2738.

13. G., P., Mengü, E., Akkuzu, 2008, Küresel Su Krizi ve Su hasadi Teknikleri, ADÜ Ziraat Fakültesi Dergisi, 5(2), 75-85.

14. https://www.rural-watersupply.net/en/resources/details/268, Assessment of Best Practises and Experience in Water Harvesting, Rainwater Harvesting Handbook.
15. B., Helmreich, H., Horn, 2009, Opportunities in rainwater harvesting, Desalination, 248, 118-124.

16.. A., D., Patel, P., K., Shah, 2015, Rainwater Harvesting- A Case Study of Amba Township, Gandhinagar, National Conference on "Transportation and Water resources Engineeirng"

17. S., Yannopoulos, G., Antoniou, M., KaiafaSaropoulou, A., N., Angelakis, 2017, Historical development of rainwater harvesting and use in Hellas: a preliminary review, Water Science \& Technology Water Supply, 17(4), 1022-1034.

18. www.dsi.gov.tr/toprak-ve-su-kaynaklari, Toprak su kaynakları, Devlet Su İşleri Genel Müdürlügü.

19. A., U., Öktem, A., Aksoy, 2014, Türkiye'nin Su Riskleri Raporu, İstanbul Bilgi Üniversitesi.

20. İçme Suyu Tesisleri Etüt Ve Fizibilite ve Projelerinin Hazırlanmasına Ait Teknik Şartname, 2013, İller Bankası Anonim Şirketi.

21. A., Karahan, 2009, Gri Suyun Değerlendirilmesi, IX. Ulusal Tesisat Mühendisliği Kongresi, 06-09 Mayıs, İzmir.

22 S Anaç ,E Özçakal ,G Pamuk Mengü Sanal Su Kavramı ve Su Yönetiminde Önemi Ege Üniv. Ziraat Fak. Derg., 2011, 48 (2): 159-164 ISSN $1018-8851$

23. G., Pegram, S., Conyngham, A., Aksoy, B., B., Divrak, D., Öztok, 2014, Türkiye'nin Su Ayak İzi Su, Üretim ve Uluslararası Ticaret İlişkisi, İstanbul Bilgi Üniversitesi.

24. www.teias.gov.tr/sites/default/files/201811/16.xlsx, Yerli Enerji Kaynaklarına ait Kurulu Gücün Türkiye Toplam Kurulu Gücü İçindeki Payının Yıllar İtibari ile Gelişimi, Türkiye Elektrik İletim A.Ş.

25. https://www.teias.gov.tr/tr/iii-elektrik-enerjisiuretimi-tuketimi-kayiplar-0, Elektrik Enerjisi Üretimi Tüketimi Kayıplar, Türkiye Elektrik İletim A.Ş.

26. http://www.dsi.gov.tr/docs/stratejik-plan/dsi2017-faaliyet-raporu.pdf?sfvrsn=2, Devlet $\mathrm{Su}$ İşleri Genel Müdürlüğü 2017 Y11ı Faaliyet Raporu.

27. M., T., Özdemir, A., Orhan, M., Cebeci, 2011, Çok Küçük Hidrolik Potansiyellerin Enerji Üretim Amacı ile Yerel İmkanların Değerlendirilmesi, Elektrik-Elektronik ve Bilgisayar Sempozyumu, Frrat Üniversitesi, Elâzı ̆̆. 


\section{Investigation of Rainwater Harvest and Hydroelectric Potential in the State Roads in Bingol Province}

\section{Extended abstract}

Fresh water resources, which can be used as an indispensable natural resource in the world; In addition to the increasing use of agricultural products for population growth and the need for food products, the need for urbanized industrialized areas negatively affects access and quality due to the increase in pollution and climate change. Water, which is the most important element of human life, is also a clean and renewable resource that will be used in the supply of electrical energy which is one of the important requirements of today's people and countries. Today, it increases its importance against fossil fuels which are used in the most amount of electricity production and are consumed day by day. In general, training on the negative impacts of access to fresh water resources in the forms of France (2012) and South Korea (2015) made with the themes of the World Water Forum 'Solution Time', 'Water for Our Future', which has been addressed in an international manner, it was stated that adequate financial resources could be reduced by water storage and rainwater harvesting, local government support, recognition of moral and ethical values and principles, and taking into account the decision-making processes in the water sector. The Global Risk Report, prepared in the World Economic Forum in 2018, states that water crises may be encountered among global risks in the future with the impacts of climate change; In addition to the efficient and economical use of precipitation water, which is the source of freshwater, it makes it necessary to make infrastructure planning which will provide the least impact on water scarcity and water crises for the future. One of the surface areas where the precipitation water will be collected by the evaporation without leakage to the underground and the least evaporation is the highway surface. With an average annual rainfall of $601 \mathrm{~mm} / \mathrm{m}^{2}$, an average of $26 \mathrm{~m}$ platform width and a wide range of other road platforms, and a total of $15600 \mathrm{~m}^{3}$ of rainwater per year can be collected from one kilometer. The collected water will meet the annual water requirement of approximately 700 people in the case of people using households and in toilets and gardens after appropriate filtration. In case of consumption of $72 \mathrm{~m}^{3}$ water per person per year; The General Directorate of Highways is responsible for $22634 \mathrm{~km}$ divided by highway and the annual rainfall average of the country will meet the annual water needs of five million people. According to the Falkenmark Indicator, our country, which is under water pressure, has the necessary infrastructure for the use of rainwater to be collected from the highway surface because of the need for more highways and roads than the developed countries. is gaining importance. The energy requirement of our country, which is under water pressure(ne demek su baskisi), has been tried to determine the hydroelectric potential of the water collected with rainwater harvesting in the parts of the mountain roads near the Bingöl City Center through the mountainous terrain. Rain water collected in the $5960 m$ of Karliova Ayr-Solhan route, which is suitable for the collection of the rain water according to the highway projects, is calculated to produce 75.940.314,85 watts of energy by transporting the rain water collected in the $5960 \mathrm{~m}$ part of the road. On the other hand, it is observed that it is not economical in terms of operating and construction costs. and therefore the rainwater harvest of the Kurudere-Bingöl, Ilicalar-Bingöl, Karliova Ayr-Solhan routes close to the Bingöl city center and this harvest; the amount of water to be collected annually and the contribution to water resources and the country's economy were investigated.

Keywords: Highway, Rainwater Harvesting, Hydroelectric Energy, Domestic Water Use. 